\section{Genetic Evaluation of Body Weight and Survival of Black Tiger Shrimp (Penaeus monodon) fed on Different Dietary Levels of Fish Meal Protein}

\author{
Song Jiang ${ }^{1,2,3}$, Xianbin Mo ${ }^{1,2}$, Falin Zhou ${ }^{2,3}$, Jianhua Huang ${ }^{2,3}$, Qibin Yang ${ }^{2,3}$, \\ Lishi Yang ${ }^{2,3}$ and Shigui Jiang ${ }^{2,3 *}$ \\ ${ }^{1}$ College of Aqua-life Science and Technology, Shanghai Ocean University, \\ Shanghai,201306, China \\ ${ }^{2}$ Key Laboratory of South China Sea Fishery Resources Exploitation and Utilization, \\ Ministry of Agriculture and Rural Affairs, P.R. China, South China Sea Fisheries \\ Research Institute, Chinese Academy of Fishery Sciences, Guangzhou, China 510300 \\ ${ }^{3}$ Shenzhen Base of South China Sea Fisheries Research Institute, Chinese Academy of \\ Fishery Sciences, Shenzhen 518108, P.R. China
}

\begin{abstract}
A B S T R A C T
The purpose of the present study is to reveal the effects of different dietary levels of fish meal protein on body weight and survival of Penaeus monodon families. In this study, 5400 P. monodon from 36 families were mixed cultureed with two kinds of different dietary levels of fish meal protein (Diet A and Diet B) for 56 days to analyze the genetic parameters of body weight and survival traits, as well as the interaction effect of genotype and environment. The results showed that the average body weight and survival rate of $P$. monodon in Diet A group were higher than those of Diet B group, and the heritability of $P$. monodon in Diet A and Diet B group was $0.53 \pm 0.12$ and $0.39 \pm 0.09$, respectively, which belonged to high heritability, and the heritability of survival after transformation was 0.38 and 0.22 , respectively, which varied from medium to high heritability. The estimated heritability of body weight and transformed survival were $0.46 \pm 0.10$ and 0.32 , respectively, which showed high heritability level. The estimates of genetic parameters might be overestimated because the common environmental effect was not included in the estimation model due to convergence problem. The results showed that there was a high genetic correlation (0.84-0.92) between Diet A and Diet B groups, and the ratio of $\mathrm{G} \times \mathrm{E}$ variance component to additive genetic variance component was less than 0.5 , and the effect of $\mathrm{G} \times \mathrm{E}$ was not significant. The results showed that although the growth and survival traits of $P$. monodon were different under different diets, the interaction effect between genotype and feed conditions was not significant. Therefore, it was not necessary to establish different breeding lines for different feed conditions in the range of $10 \%-30 \%$ protein level of feed fish meal.
\end{abstract}

\begin{tabular}{l} 
Article Information \\
Received 02 January 2020 \\
Revised 14 May 2020 \\
Accepted 20 June 2020 \\
Available online 25 August 2021 \\
Authors' Contribution \\
SGJ, SJ and XBM designed the \\
study. QBY and JHH took part in \\
the execution of study. LSY, QBY \\
and XBM implemented the study \\
and involved in sampling as well as \\
testing. SJ, XBM and SGJ drafted the \\
manuscript. All the authors read and \\
accepted the final manuscript before \\
submission. \\
Key words \\
\hline Penaeus monodon, Fish meal, Body \\
weight, Heritability G×E interaction
\end{tabular}

\section{INTRODUCTION}

$\mathrm{T}$ he black tiger shrimp (Penaeus monodon, Crustacea, Decapoda, Penaeidae) is an economically and globally important marine species, and very important in the aquaculture industries in China. At present, there are only "Nanhai No.1" and "Nanhai No.2" in China, but these two new varieties are selected with the goal of fast growth and high survival rate (Huang et al., 2009, 2012). P. monodon is a kind of omnivorous shrimp and in the process of culture, $P$. monodon requires high protein content in the diet. Previous studies have shown that the optimal protein

\footnotetext{
* Corresponding author: 515641795@qq.com 0030-9923/2021/0006-2007 \$ 9.00/0

Copyright 2021 Zoological Society of Pakistan
}

content in the feed of $P$. monodon is about $30 \%-50 \%$, and the optimal protein demand of $P$. monodon cultured in seawater is about 40\% (Miao et al., 2001; Wang et al., 1998). Fish meal is the main source of protein in aquatic feed, with the decrease of fish meal resource year by year, feed cost is increasing year by year. From the point of view of genetic breeding, breeding a new variety of $P$. monodon suitable for low fish meal protein level feed culture will fundamentally solve this problem.

The phenotypic traits of animals are influenced not only by genetic factors, but also by environmental factors. The study on the growth characteristics of economic species under different diets can better understand the growth characteristics of species, explore the most suitable breeding environment, and provide reference information for improving varieties and improving the adaptability 
of varieties under the feeding environment of ground protein level. At present, the breeding objectives of shrimp breeding mainly focus on growth, survival, disease resistance and stress resistance (Jiang et al., 2013). Feed is one of the important factors affecting the growth and survival of P. monodon. Penaeus monodon has adapted to a wide range of diet protein level, but extreme low fish meal protein level diet can have a significant impact on them (Jiang et al., 2013). Therefore, the selection and breeding of $P$. monodon on low fish meal protein diet need further study, including the genetic parameters of growth and survival traits and the interaction effect of genotype and environment. In this study, we analyzed the genetic parameters and $\mathrm{G} \times \mathrm{E}$ effects of body weight and survival of $P$. monodon fed with two kinds of diets, and analyzed whether there was reordering effect of different fish meal protein levels in feeding environment by quantitative genetic method, and whether it was necessary to establish breeding core population separately for different diets. The results provide a theoretical reference for the selection of P. monodon.

\section{MATERIALS AND METHODS}

\section{Experimental materials}

The P. monodon used in this study was from the whole sib family constructed in 2019 , and the male and female broodstock were selected from the $P$. monodon strains kept in 2018. By controlling the inbreeding scheme design, the next generation families were obtained.

\section{Family construction}

After determining the family construction plan, the artificial insemination technology was used to construct the P. monodon families. When the gonads of female shrimp were mature, the sperm pods were transplanted into the seminal vesicle, and then the female broodstock were transferred into independent units to lay eggs. The incubation temperature of eggs was controlled at about $30^{\circ} \mathrm{C}$. After hatching the fertilized eggs, about 8000 nauplii were collected from each independent unit and transferred to $500 \mathrm{~L}$ polyethylene fiber barrel for cultivation. When the nauplius was cultured to the larval stage, 3000 shrimps were taken and transferd to a $1 \mathrm{~m}^{3}$ cement tank for cultivation. When the larvae were cultured to the 15 th day, 500 of them were taken out and transferred to $500 \mathrm{~L}$ polyethylene fiber barrel for intermediate cultivation. When the average body length of young shrimp was $3 \mathrm{~cm}$, each family was labeled by injecting color fluorescent dye into the sixth ventral segment.
Cultivation of $\mathrm{P}$. monodon in different diets

After fluorescence labeling, the initial body weight of each shrimp was measured and 50ind P. monodon of each family was evenly distributed to six different cement tanks $(5 m \times 4 m \times 2 m)$ for mixed culture. During the period, Diet A (fish meal content in feed was 30\%) and Diet B (fish meal content in feed was $10 \%$; concentrated dephenolized cottonseed protein content was 20\%) (Table I) were regularly fed three times a day, the daily feeding amount was about $8 \%$ of the body weight of shrimp, and the water was regularly changed every day, and the volume of water change accounted for one third of the total water body. The body weight and survival rate of $P$. monodon were measured after $56 \mathrm{~d}$ of mixed culture. The death rate was counted after the experiment (Table II).

Table I. Composition and nutrient content of experimental diets.

\begin{tabular}{|c|c|c|}
\hline Ingredients(\%) & Diet A & Diet B \\
\hline Fish meal & 30 & 10 \\
\hline Soybean meal & 18 & 18 \\
\hline $\begin{array}{l}\text { Concentrated dephenolization cottonseed } \\
\text { protein }\end{array}$ & 0 & 20 \\
\hline Peanut meal & 10 & 10 \\
\hline Wheat flour & 21.99 & 17.1 \\
\hline Beer yeast & 3 & 3 \\
\hline Shrimp head meals & 5 & 5 \\
\hline Soybean protein concentrate & 4.8 & 6.2 \\
\hline Soybean lecithin & 1 & 1 \\
\hline Fish oil & 1 & 1 \\
\hline Soybean oil & 0.5 & 2.1 \\
\hline CAscorbic Phosphate ester & 0.1 & 0.1 \\
\hline Cholesterol & 0.5 & 0.5 \\
\hline Vitamin premix ${ }^{a}$ & 1 & 1 \\
\hline Mineral premix ${ }^{b}$ & 1 & 1 \\
\hline $\mathrm{Ca}\left(\mathrm{H}_{2} \mathrm{PO}_{4}\right)_{2}$ & 1 & 1 \\
\hline Lysine & 0 & 0.97 \\
\hline Methionine & 0.1 & 0.47 \\
\hline Threonine & 0 & 0.55 \\
\hline Carboxymethylcellulose & 1 & 1 \\
\hline $\mathrm{Y}_{2} \mathrm{O}_{3}$ & 0.01 & 0.01 \\
\hline Sum & 100 & 100 \\
\hline \multicolumn{3}{|l|}{ Proximate composition } \\
\hline Moisture(\%) & 8.32 & 7.88 \\
\hline Crude protein( $(\%)$ & 48.65 & 48.29 \\
\hline Crude lipid(\%) & 5.70 & 6.09 \\
\hline $\operatorname{Ash}(\%)$ & 11.89 & 10.47 \\
\hline
\end{tabular}

Note: 1. Vitamin premix $\left(\mathrm{g} \cdot \mathrm{kg}^{-1}\right): \mathrm{V}_{\mathrm{A}} 2.5 ; \mathrm{V}_{\mathrm{D}} 6.25 ; \mathrm{V}_{\mathrm{E}} 75 ; \mathrm{V}_{\mathrm{K}} 2.5 ; \mathrm{V}_{\mathrm{B} 1} 0.25$; $\mathrm{V}_{\mathrm{B} 2} 1.0 ; \mathrm{V}_{\mathrm{B} 3} 5.0 ; \mathrm{V}_{\mathrm{B} 6} 0.75 ; \mathrm{V}_{\mathrm{B} 12} 2.5$; folic acid 0.25 ; biotin 2.5; inositol 379 ; cellulose 500; 2. Mineral premix $\left(\mathrm{g} \cdot \mathrm{kg}^{-1}\right): \mathrm{KCl}, 90$; $\mathrm{KI} 0.04, \mathrm{NaCl}, 40 \mathrm{~g}$; $\mathrm{CuSO}_{4} \cdot 5 \mathrm{H}_{2} \mathrm{O}, 3 ; \mathrm{ZnSO}_{4} \cdot 7 \mathrm{H}_{2} \mathrm{O}, 4 ; \mathrm{CoSO}_{4} \cdot 7 \mathrm{H}_{2} \mathrm{O}, 0.02 ; \mathrm{FeSO}_{4} \cdot 7 \mathrm{H}_{2} \mathrm{O}, 20$; $\mathrm{MnSO}_{4} \cdot \mathrm{H}_{2} \mathrm{O}, 3 ; \mathrm{MgSO}_{4} \cdot 7 \mathrm{H}_{2} \mathrm{O}, 124 ; \mathrm{Ca}\left(\mathrm{H}_{2} \mathrm{PO}_{4}\right)_{2} \cdot 2 \mathrm{H}_{2} \mathrm{O}, 500 ; \mathrm{CaCO}_{3}, 215$. 


\section{Statistical analysis}

A linear mixed model was established and the average information restricted maximum likelihood was used to estimate the body weigth variance components of P. monodon by asreml 4 software.

Individual animal model was used as breeding analysis model.

$\mathrm{y}_{\mathrm{ijkl}}=\mu+\operatorname{Env}_{\mathrm{i}}+\operatorname{Sex}_{\mathrm{j}}+\operatorname{Env}_{\mathrm{i}} \times \operatorname{Sex}_{\mathrm{j}}+\mathrm{b}_{1} \mathrm{Wt}_{\mathrm{k}}\left(\operatorname{Env}_{\mathrm{i}} \times \operatorname{Sex}_{\mathrm{j}} \times\right.$ Tank $\left._{\mathrm{l}}\right)+\mathrm{a}_{\mathrm{k}}+\mathrm{a}_{\mathrm{k}}\left(\right.$ Env $\left._{\mathrm{i}}\right)+\mathrm{e}_{\mathrm{ijkl}} \ldots(1)$

In formula, $y_{i j k l}$ was the body weight observation value of the $\mathrm{k}$-tailed shrimp; $\mu$ was the mean of body weight. $E n v_{i}$ was the fixed effect of the i-th breeding diet. $S e x_{j}$ was the fixed effect of the j-th personality. Env ${ }_{i} \times \operatorname{Sex}$ was the interactive fixed effect of the i-th diet and the $\mathrm{j}$-th personality. $W t_{k}$ was the body weight (covariance) of the k-tailed shrimp before mixed cultivation in $E n v_{i} \times \operatorname{Sex}_{j} \times \operatorname{Tank}_{l}$, where $b_{1}$ was the regression coefficient and $\operatorname{Tank}_{l}$ was the $l$-th test pool. $a_{k}$ was the regression coefficient of the additive genetic effect of k-tailed shrimp body weight. $a_{k}$ was the additive genetic effect of k-tailed shrimp weight, and $a_{k}(E n v)$ was the additive effect of k-tailed shrimp nested in the i-th culture diet. $e_{i j k}$ was the random residual of body weight of the k-tailed shrimp.

Model (1) was used to estimate the variance components of genotype environment interaction effect, $E n v_{i}$ and $a_{k}\left(E n v_{i}\right)$ effects were removed from model (1) to estimate the variance components and heritability of Diet $\mathrm{A}$ and Diet $\mathrm{B}$ respectively. $a_{k}\left(E n v_{i}\right)$ was removed from model (1) to set the weight of Diet A and Diet B as independent residuals. CORGH variance (covariance) structure was used to estimate the genetic correlation of body weight between Diet A and Diet B groups. In the model (1), the fixed effect of the test pool were included and the statistical test was not significant, including the random effect of the full-sib group were included and the model did not converge, so the two effects were not included in the model.

After the family growth test, the surviving individuals were recorded as 1 and the dead individuals as 0 . The variance components of survival traits were estimated by using the generalized linear mixed model (probit). The breeding analysis model was male and female animal model:

$$
\operatorname{Pr}\left(\mathrm{y}_{\mathrm{hijk}}=1\right)=\operatorname{Pr}\left(\mathrm{l}_{\mathrm{hijk}}>0\right)=\varphi\left[\mu+\operatorname{Env}_{\mathrm{h}}+\operatorname{Tank}_{\mathrm{l}}+\mathrm{s}_{\mathrm{i}}+\mathrm{d}_{\mathrm{j}}+\mathrm{s}_{\mathrm{i}}\right.
$$
$\left.\left(\operatorname{Env}_{\mathrm{h}}\right)+\mathrm{d}_{\mathrm{j}}\left(\mathrm{Env}_{\mathrm{h}}\right)\right] \quad \ldots(2)$

In the formula, $y_{h i j k l}$ was the survival state of the k-tailed shrimp (1 was survival, 0 was death), $l_{h i j k}$ was the potential variable, $y_{h i j k l}=1$ if $l_{h i j k}>0, y_{h i j k l}=0$ if $l_{h i j k} \leq 0, \mu$ was the overall mean, $E n v_{h}$ was the fixed effect of the h-th culture diet, Tank $k_{l}$ was the fixed effect of the $l$-th test pool, $s_{i}$ was the additive genetic effect of the i-th male parent, $d_{j}$ was the additive genetic effect of the $\mathrm{j}$-th female parent,
$s_{i}\left(E n v_{h}\right)$ and $d_{j}\left(E n v_{h}\right)$ were the male and female parent effects nested in the h-th field.

The model 2 was used to estimate the variance components of interaction effect between genotype and environment. The $E n v_{h}, s_{i}\left(E n v_{h}\right)$ and $d_{j}\left(E n v_{h}\right)$ effects were eliminated from the model (2), and the variance components and heritability of Diet A and Diet B survival were estimated respectively. The $E n v_{h}, s_{i}\left(E n v_{h}\right)$ and $d_{j}\left(E n v_{h}\right)$ effects were eliminated from the model (2), and Diet A and Diet B survival was set as independent residuals. CORGH variance (covariance) structure was used to estimate the genetic correlation of body weight between Diet A and Diet B groups. In model (2), including the full-sib group random effect, the model was not convergent, considering that the proportion of half-sib families was low, and only one generation pedigree, so the effect was eliminated in the model.

Heritability of weight traits $\left(h^{2}\right)$ :

$$
h^{2}=\sigma_{\alpha}^{2} /\left(\sigma_{\alpha}^{2}+\sigma_{e}^{2}\right)
$$

Heritability of survival $\left(h^{2}\right)$ :

$$
h^{2}=4 \sigma_{s d}^{2} /\left(2 \sigma_{s d}^{2}+\sigma_{e}^{2}\right)
$$

The heritability of the survival traits estimated by the threshold model of male and female animals would be higher than the actual value, so the method proposed by Dempster was used to transform.

The ratio of variance components of genotype environment interaction and additive genetic variance components of weight traits $(K)$ :

$$
K=\sigma_{\alpha e}^{2} / \sigma_{\alpha}^{2}
$$

The ratio of variance components of genotype environment interaction and additive genetic variance components of survival $(K)$ :

$$
K=\sigma_{s d e}^{2} / \sigma_{s d}^{2}
$$

If $K>0.50, \mathrm{G} \times \mathrm{E}$ effect was significant; if $K \leq 0.50$, $\mathrm{G} \times \mathrm{E}$ effect was not significant. In the formula, $\sigma^{2}{ }_{a}$ was the variance component of body weight additive heredity, $\sigma_{s d}^{2}$ was the mean of variance component of male and female livestock of survival character. It was set that male and female heredity were completely related and equal. It was realized by SAReml's and function. The $\sigma_{a e}^{2}$ and $\sigma_{\text {sde }}^{2}$ were the variance component of body weight and the interaction between the survival active gene and environment respectively, and $\sigma_{e}^{2}$ was the residual variance component.

Z-score was used to test whether there was significant difference in heritability between Diet A and Diet B, 
and also to test whether there was significant difference between genetic correlation and 1 (complete correlation) between different fields.

$$
Z=\left(x_{i}-x_{j}\right) / \sqrt{\sigma_{i}^{2}+\sigma_{j}^{2}}
$$

In the formula, $x_{i}$ and $x_{j}$ were the heritability of body weight or survival traits of Diet A and Diet B groups respectively, and $\sigma_{i}^{2}$ and $\sigma_{j}^{2}$ were the standard errors of corresponding heritability respectively. When testing whether the genetic correlation between groups was significantly different from $1, \sigma_{i}$ and $\sigma_{j}$ are set to 1 and 0 respectively.

\section{RESULTS}

Descriptive statistics of body weight and survival traits

The mean body weight of $P$. monodon in Diet A group was significantly higher than that in Diet B group $(P<0.05)$, and the mean survival rate of $P$. monodon in Diet A group was significantly higher than that in Diet $\mathrm{B}$ group $(P<0.05)$. The coefficient of variation of nodal body weight and survival rate in Diet B group was higher than that in Diet A group (Table II).
Genetic parameters and $G \times E$ effect of body weight and survival rate of $\mathrm{P}$. monodon in different feed groups

The heritability estimates of body weight of $P$. monodon were $(0.53 \pm 0.12)$ and $(0.39 \pm 0.09)$ (Table III), which belong to high heritability $\left(h^{2} \geq 0.30\right)$; the actual heritability estimates of survival traits after transformation were 0.38 and 0.22 , which also showed medium and high heritability $\left(h^{2} \geq 0.15\right)$. The heritability of body weight and survival traits after transformation estimated by Diet A and Diet B were $(0.58 \pm 0.08)$ and 0.32 , respectively, which showed high heritability $\left(h^{2} \geq 0.30\right)$. Z-scroe test showed that all heritability estimates reached a significant level $(P<0.05)$; the difference between the weight heritability of Diet A and Diet B groups reached a significant level $(P<0.05)$, and the difference between the heritability of survival traits was not significant $(P>0.05)$.

The genetic correlation coefficient of weight between Diet A and Diet B was $0.92 \pm 0.06$, and there was a high linear positive correlation between the two groups. The genetic correlation coefficient of survival traits between Diet A and Diet B was $0.84 \pm 0.08$, and the survival rate of the two feed groups was highly linear and positive. The $\mathrm{K}$-values of body weight and survival rate traits were 0.18 and 0.12 , respectively. The $\mathrm{G} \times \mathrm{E}$ effect of the two traits was not significant $(K<0.05)$.

Table II. Effect of differnt diet levels on the body weight and survival rate of $P$. mondon groups.

\begin{tabular}{llllll}
\hline Traits & Diet & $\begin{array}{l}\text { Sample } \\
\text { number } / \text { ind }\end{array}$ & $\begin{array}{l}\text { Minimum- } \\
\text { Maximum }\end{array}$ & Mean \pm SD & \multicolumn{2}{c}{$\begin{array}{l}\text { Coefficient of variation } \\
\text { (\%) }\end{array}$} \\
\hline Body weight/g & A & 1209 & $3.23-18.34$ & $13.08 \pm 2.97$ & 22.71 \\
& B & & $2.96-16.22$ & $11.21 \pm 2.97$ & 22.84 \\
Survival rate/\% & A & 1168 & $72.51-86.52$ & $80.59 \pm 10.21$ & 12.67 \\
& B & & $70.68-84.65$ & $77.88 \pm 10.20$ & 13.10 \\
\hline
\end{tabular}

Table III. Effect of commercial diet and low fishmeal diet environment on genetic parameter for body weight and survival rate of $P$. mondon.

\begin{tabular}{lllll}
\hline Parameter & Diet & & REML estimated value \\
\cline { 3 - 5 } & & Body weight & Survival rate $\begin{array}{c}\text { Survival rate } \\
\text { (converted value) }\end{array}$ \\
\hline$h^{2}$ & $\mathrm{~A}+\mathrm{B}$ & $0.46 \pm 0.10$ & $0.58 \pm 0.08$ & 0.32 \\
& $\mathrm{~A}$ & $0.53 \pm 0.12$ & $0.64 \pm 0.07$ & 0.38 \\
& $\mathrm{~B}$ & $0.39 \pm 0.09$ & $0.48 \pm 0.09$ & 0.22 \\
Diet A+ Diet B genetic correlation & & $0.92 \pm 0.06$ & $0.84 \pm 0.08$ \\
Ratio of genotype-environment interaction variance & & $\sigma_{a e}^{2}=1.18$ & $\sigma_{s d e}^{2}=0.023$ \\
to additive genetic variance $(K)$ & & $\sigma_{a}^{2}=7.26$ & $\sigma_{s d}^{2}=0.26$ \\
& & $K=0.18$ & $K=0.12$ \\
\hline
\end{tabular}




\section{DISCUSSION}

As a traditional breeding method, selective breeding technology had been widely used in the study of animal and plant genetic improvement, and had become one of the effective means of breeding new varieties and new lines (Lou, 2001). Family selection was a kind of important means of selection and breeding ( $\mathrm{Li}, 2007)$. Through the directional construction of families and the performance test under the common environment, the selection between families and within families, and the breeding according to the pedigree and the performance test results during the subculture, the effect of inbreeding controllable and sustainable breeding could be achieved. The technology of family selection and breeding had been applied in many aquatic animals and cultivated breeding a large number of good aquatic animals (Luo et al., 2015; Chen et al., 2008; Gao et al., 2010; Zhang et al., 2007, 2008), which had become one of the most important breeding methods.

All aquatic animals had a certain range of adaptation to the protein content in the diet and they were able to survive and grow normally within the appropriate range of protein content. If the protein content in the feed was too high or too low, it would affect the survival rate and normal growth of aquatic animals (Paripatananont et al., 2015). In the condition of $P$. monodon artificial culture, the fish meal protein content in its feed was generally $30 \%$ $50 \%$ (Jiang et al., 2013). However, the growth rate and survival rate of $P$. monodon fed with different fish meal protein content were quite different (Jiang et al., 2013). In this experiment, there were significant differences in the growth of different $P$. monodon families when they are fed the same fish meal protein level feed, and there were very significant differences among individual families, which was consistent with the previous research results on $P$. monodon. Zhang (Zhang et al., 2007) also obtained similar research results on the family of Penaeus chinensis, and there were significant differences in the growth of different family of $P$. chinensis in the development period. This showed that there were differences in gene level among different families of $P$. monodon, so different families were good breeding materials.

Kenway estimated that the heritability of $P$. monodon was $0.36-0.71$, Zhou estimated that the heritability of ammonia nitrogen tolerance and low salt tolerance of $P$. monodon were $0.11 \pm 0.04$ and $0.29 \pm 0.08$, respectively. In this study, the results showed that the heritability of body weight traits of $P$. monodon was high in both diets, which indicated that the breeding goal of improving economic traits of $P$. monodon could be achieved by breeding. However, due to convergence, common environmental effects were not included in the estimation model, so the estimated values of the genetic parameters of body weight and survival rate in this study were both high. Different families of the same economic species had different adaptability to the environment, and might have strong genotype environment interaction effect. There was a strong interaction between genotype and environment in the growth and survival traits of $P$. monodon. Studies had shown that different $P$. monodon families had different sensitivity to the change of food range. There were different families with obvious or not obvious differences in body weight with the change of food protein level. This result showed that there were differences in the optimal growth level of feed protein among different $P$. monodon families. However, this study showed that the genetic correlation coefficient between the two fish meal protein diets was high and the $\mathrm{G} \times \mathrm{E}$ effect was not significant. In view of the medium fish meal protein level feed culture environment, only one breeding line could be established to develop a new variety (line) of P. monodon with high growth rate and high survival rate. However, in this study, the low fish meal feed was only the feed containing $10 \%$ fish meal protein, and the feed with lower fish meal protein level was not tested. Due to the large difference between different feed groups, there might be stronger interaction effect between genotype and environment, which would be further analyzed in the follow-up study.

\section{ACKNOWLEDGMENTS}

This study was supported by the National Key R\&D Program of China (2018YFD0901302), Central Publicinterest Scientific Institution Basal Research Fund, South China Sea Fisheries Research Institute, CAFS (NO. 2020ZD01), Industrial Technology System of Modern Agriculture (CARS-48), Guangdong Provincial Special Fund for Modern Agriculture Industry Technology Innovation Teams (No. 2019KJ149).

\section{Statement of conflict of interest}

The authors have declared no conflict of interests.

\section{Data availability statement}

The data that support the findings of this study are available on request from the corresponding author.

\section{REFERENCES}

Chen, S.L., Tian, Y.S., Xu, T.J., Deng, H., Liu, S.T., Liu, B.W., Ji, X.S. and Yu, G.C., 2008. Development and characterization for growth rate and disease resistance of disease-resistance population and family in Japanese flounder Paralichthys olivaceus. 
J. Fish. China, 32: 665-673.

Gao, B.Q., Liu, P., Li, J., Dai, F.Y. and Wang, X.Z., 2010. Growth comparison between families of Portunus trituberculatus. Period. Ocean Univ. China, 40: 47-51.

Huang, J.H., Li, Y., Yang, Q.B., Su, T.F., Zhu, C.Y. and Jiang, S.G., 2012. Comparison of tolerance to ammonia-N in Penaeus monodon families. South China Fish. Sci., 8: 37-43.

Huang, Z., Lin, H.Z., Huang, J.H., Yang, Q.B., Wen, W.G., Chen, X., Zhou, F.L. and Jiang, S.G., 2009. Growth, feed utilization and whole-body composition of six Penaeus monodon families. South China Fish. Sci., 5: 42-47.

Jiang, S., Huang, J.H., Lin, H.Z., Yang, Q.B., Zhou, F.L., Qiu, L.H., Su, T.F. and Jiang, S.G., 2013. Effects of dietary protein levels on the growth and survival of Penaeus monodon from different families. $J$. Shanghai Ocean Univ., 22: 349-356.

Kenway, M., Macbeth, M., Salmon, M., McPhee, C., Benzie, J., Wilson, K. and Knibb, W., 2006. Heritability and genetic correlations of growth and survival in black tiger prawn Penaeus monodon reared in tanks. Aquaculture, 259: 138-145. https:// doi.org/10.1016/j.aquaculture.2006.05.042

Li, Y.F., 2007. Application of family selection in aquatic animals. J. Beijing Fish., 5: 44-46.

Lou, Y.D., 2001. Fish breeding. Chinese Agricultural Press, Beijing. Pp. 102-106.

Luo, K., Xia, Y.T., Wang, B., Kong, J., Su, X.X., Xu,
S.J. and Zhang, D.H., 2015. Construction and comparison in growth performance among different families of Acipenser gueldenstaedtii. Oceanol. Limnol. Sin., 46: 464-469.

Miao, Y.T., Wang, W.N., Wang, A.L. and Hu, J.R., 2001. Research progress on nutritional requirements of Penaeus monodon. Fish. Sci. Technol. Inf., 28: 207209.

Paripatananont, T., Boonyaratpalin, M., Pengseng, P. and Chotipuntu, P., 2015. Substitution of soy protein concentrate for fishmeal in diets of tiger shrimp Penaeus monodon. Aquacult. Res., 32: 369-374. https://doi.org/10.1046/j.1355-557x.2001.00045.x

Wang, H.W., Wang, A.L. and Wang, L.N., 1998. Oversea research on nutrition of Penaeus monodon. J. Hebei Univ., 18: 98-104.

Zhang, C.S., Yang, X.G., Song, J., Jiang, S.G. and Yin, X.X., 2008. Establishment of families and their early growth of Japanese scallop (Patinopecten yessoensis). South China Fish. Sci., 4: 44-50.

Zhang, T.S., Kong, J., Liu, P., Wang, Q.Y., and Zhang, Q.W., 2007. Preliminary study of establishment of families and their growth and development for Fenneropenaeus chinensis. Acta Oceanol. Sin., 29:120-124.

Zhou, F.L., Yang, Q.B., Huang, J.H., Jiang, S., Yang, L.S., Zhang, T.S. and Jiang, S.G., 2019. Estimation of genetic parameters for ammonia nitrogen and freshwater tolerance traits in Penaeus monodon. South China Fish. Sci., 15: 63-68. 